\title{
Performance Analysis of Solar Tray Dryer for Cassava Starch
}

\author{
Suherman Suherman*, Mohammad Djaeni, Dyah H. Wardhani, Mukhtar Dzaki R, and Muhammad N. Bagas F \\ Department of Chemical Engineering, Faculty of Engineering, Diponegoro University, J1. Prof. Soedarto, SH Tembalang, Semarang, \\ Indonesia 50239
}

\begin{abstract}
The main objective of this study is to analyze the performance of solar tray dryyer for cassava starch. The solar tray dryer is made of glass and iron shaped dryer and box, where the solar collector is made of black painted iron plate. The initial moisture content of cassava starch is $50 \%$ wet bases. The experimental result show the moisture content of starch decrease rapidly in 8 hours of drying the first day until $14 \%$ moisture content. Further drying able to dry starch to $8 \%$ water content. The water temperature in solar dryer can reach $60^{\circ} \mathrm{C}$ was higher than the ambient of $32^{\circ} \mathrm{C}$. Furthermore, the air humidity relative in the solar dryer can drop dramatically to $30 \%$ is lower than the ambient $80 \%$. Maximum drying rate can reach up to $0.2 \mathrm{~g} / \mathrm{h}$. Thermal efficiency of the dryer can reach $40 \%$. The performance of this solar dryer is much better than the sun dryer which veing piloted in this study
\end{abstract}

\section{Introduction}

Drying cassava flour using solar drying have been developed in several countries such as Thailand, while in Indonesia itself is still using conventional drying is dried by relying on sunlight, Solar drying is a method or way of drying a food using solar radiation energy, this method is the most inexpensive and easily as using direct heat from the sun. Solar drying is assisted simple tools and a chamber as a place of the drying. Solar drying is shaped like a closed room with transparent walls. With the closing of this tool, it can avoid the contaminants from the surrounding environment. At the bottom will be placed a rectangular heat collector painted black.

There is a lot of research on drying cassava flour that has been done before with a wide range of prototype devices. Mixed flow dryer (Olawale et al., 2015); pneumatic conveying dryer (Aichayawanich S. et al., 2011); rotary dryer (FT Ademiluyi et al., 2010); tray dryer (Ndubisi et al., 2014); spray dryer (Monica and Anibal, 2014); convection solar dryers (Tarin et al., 2005); indirect solar dryers (Azimi et al., 2012). This study investigated the drying characteristics of cassava flour with a variety of different treatments by the drying temperature and drying efficiency. However, the earlier study relied more prototype tool that tends to be more expensive. There's drying solutions is by sun drying or natural drying whose treatment is only necessary to drying under the sun, but is inefficient and requires a long drying time.

In research conducted by Anhalt (2003) entitled "The use of Renewable Energy in the Production of Goods: Seaweed" indicates that the natural drying process usually takes a long time because the temperature and energy dependent on sunlight. In addition, the effects of weather, season, and the change of day and night to make this process more and more limited. If the weather conditions do not support the increasingly high water content so that it can be mold and mildew growth media. Moreover, if the drying is done in the open. This will trigger the presence of contaminants that degrade the quality of tapioca starch products, such as dust, dirt or foreign objects are not desired. Based on the problems it is necessary to have a technology development efforts that are efficient, effective and efficient in drying starch. These efforts are expected to reduce the water content in accordance default, the drying process is faster, does not depend only on the energy of the sun, the weather and climate of the local area.

\section{Materials and Methods}

\subsection{Materials}

Materials (samples) were used and tested is starch (wet basis), was taken from the SME starch in Pati, Central Java. For drier (solar dryers), the material used in the form of metallic aluminum conductors, transparent Acrylic, zinc, iron, rubber and bolts. The equipment used during the testing period, among others timepiece, digital weight scale, a thermometer, and an oven

\footnotetext{
Corresponding author: suherman.mz@che.undip.ac.id
} 


\subsection{Drying Equipment}
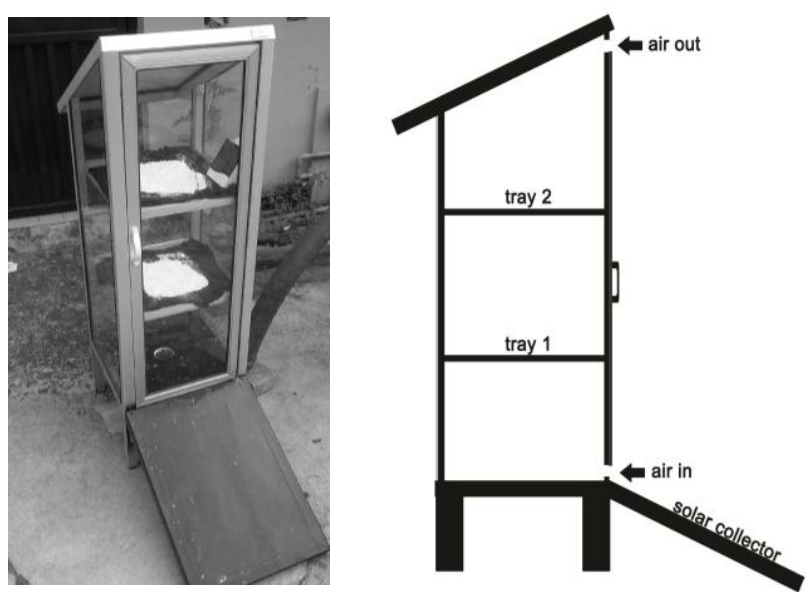

Fig. 1. Solar Tray Dryer

The prototype of Solar dryer has a dimension 40x40×150 $\mathrm{cm}$. The materials used in the manufacture of the prototype of Solar dryer has some special characteristics. First, choose materials affordable to expectations in its application were able to save cost from the price. Second, lightweight materials to facilitate the operation of the device itself, for example if you want to be moved or taken to another place. Third, the selected material has the properties of heat collectors. With these properties then the heat will accumulate inside the tool so that it can speed up the drying process. This tool is also made of a material that is not easily broken, broken or porous so as to reduce the risk of damage and loss. Aluminum is used as the framework is a good conductor of heat, light and affordable.

Drier is made in the form of shelves in order to have a drying capacity of the lot. The roof is sloped so that when it rains, the water can drip down easily so it will not wet the dried material. In addition, the slope of the roof is water vapor attached to the roof produced during drying is expected to easily flow out through the roof and walls so that the dried material will be protected from water vapor that condenses droplets. On the roof there is a hole as a water vapor expenditure, the purpose is that water vapor formed during the drying process may soon be out of the appliance. Solar dryer is shaped like a closed room with transparent walls. With the closing of this tool, it can avoid any contamination from the surrounding environment. At the bottom of the tool will be placed a heat collector rectangular painted black.

\subsection{Research Procedure}

Research tapioca starch drying is done according to the procedure of the first is the early preparation stage. Initial preparation phase aims to wet starch by preparing samples of starch (wet basis) and weigh the wet base sample (100 grams). Then the drying step is done by setting up a solar dryer tray dryer and prepare 100 grams of starch. Put the tapioca flour (wet basis) on a tray in a tray dryer solar appliance. Please note the change of tapioca flour weight every hour for 8 hours within 2 days. Take measurements of temperature, moisture content, drying rate, dryer efficiency, relative humidity.

\subsection{Experimental Data Analysis}

\subsubsection{Temperature measurement}

Each 100 grams sample is placed on each tray on the solar dryer. Measuring the temperature every 1 hour on each tray for 8 hours, measure the temperature at the inlet, outlet, ambient temperature and the temperature of the drying chamber operating solar dryers. Then be concluded associated with operating time. We get the graph of temperature relation with time

\subsubsection{Analysis of moisture content}

To determine the moisture content, we have to get the data of weight per hour at each tray by weighing the sample on each tray every 1 hour then obtained graph relation of moisture content with time, for example:

$$
M_{\mathrm{c}}(\text { wet basis })=\left[\left(M_{\mathrm{i}}-M_{\mathrm{d}}\right) \div M_{\mathrm{i}}\right] \times 100 \%
$$

(Mi) is the mass of the sample after drying for 1 hour, (Md) is the mass of dry basis.

\subsubsection{Analysis of drying rate}

To obtain the drying rate, it requires data sample of weight on each tray. By using equation (Dhanushkodi Saravanan, 2004). Then the drying rate obtained graph with time.

$$
R_{\mathrm{d}}=\left(M_{\mathrm{i}}-M_{\mathrm{d}}\right) \div t
$$

$$
\begin{aligned}
\text { Dimana : } & \mathrm{Rd}=\text { drying rate } \\
\mathrm{Mi} & =\text { initial mass } \\
\mathrm{Md} & =\text { final mass } \\
\mathrm{t} & =\text { drying time }(\mathrm{s})
\end{aligned}
$$

\subsubsection{Analysis of relative humidity}

To determine the relative humidity, using a hygrometer or use the measurement method Tw and Td. Tw is the wet bulb temperature, which is measured by measuring the temperature of the wet with wet cotton stick on the tip of the thermometer. While $\mathrm{Td}$ is dry bulb temperature, which is measured by measuring the temperature of the usual dry. By connecting Td and Tw on psychometric chart will be obtained per cent RH.

\subsubsection{Analysis of dryer efficiency}

To measure dryer efficiency, using the equation :

$$
\left.\eta_{\mathrm{c}}=\left[m C_{\mathrm{p}}\left(T_{\mathrm{o}}-T_{\mathrm{i}}\right)\right] \div I x A\right]
$$

Dimana : To = outlet temperature

$$
\mathrm{Ti}=\text { inlet temperature }
$$




$$
\begin{array}{ll}
\mathrm{M} & =\text { air flowrate } \\
\mathrm{I} & =\text { solar intensity, from the reference } \\
\mathrm{A} & =\text { area of heat collector }
\end{array}
$$

The temperature is measured every hour and graphed the relation of dryer efficiency with time

\section{Results and Discussion}

\subsection{Temperature profile and humidity of Solar Dryer}

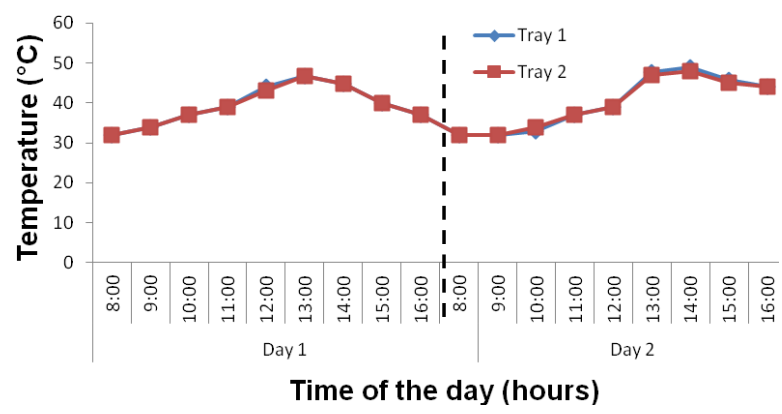

Fig. 2. Temperature and Drying Time of Solar Drying

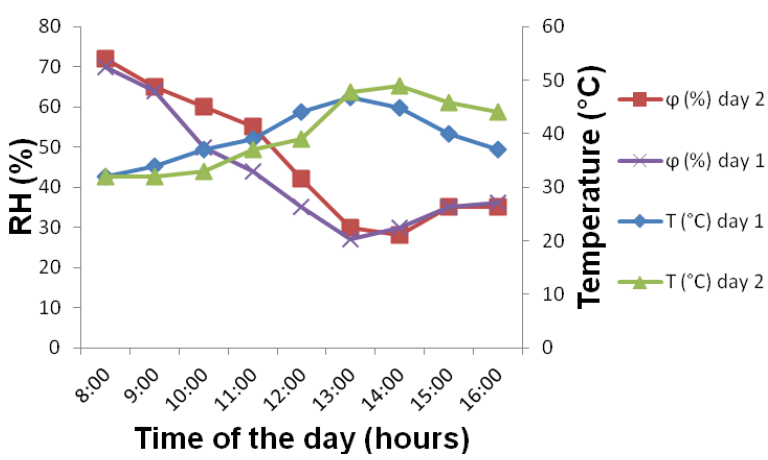

Fig. 3. Temperature and Humidity Average with Drying Time in Solar Drying Method

Based on the figure (2) shows the fluctuation of dryer temperature. The maximum dryer temperature on the first day was $44.8^{\circ} \mathrm{C}$ at $14: 00 \mathrm{pm}$ and dryer temperature minimum on the first day was $32^{\circ} \mathrm{C}$ at $08.00 \mathrm{pm}$. The maximum dryer temperature of the second day was $49^{\circ} \mathrm{C}$ on a tray 1 and $48^{\circ} \mathrm{C}$ at the tray 2 when at $14.00 \mathrm{pm}$. The minimum temperature dryer on the second day was $32^{\circ} \mathrm{C}$ at $08.00 \mathrm{pm}$. This is influenced by the weather and time of drying. In fine weather the sun is absorbed by optimal because no clouds blocked. In addition it will be effective and optimal drying if done during the day, particularly at 11:00 am until 14:00 pm. At the time of the emitted light intensity is strong enough. In the tray 1 and tray 2 having a bit of difference in temperature at which the tray 1 is located at the bottom and the tray 2 is at the top. This causes the heat from the heat collector leads directly to the tray 1 first and then passed to tray 2 so that the temperature of the tray 1 higher. This tool borrows the concept of green house that aims to trap heat. Heat from the sun is absorbed by the tool but is not directly reflected off the tool, but is reflected back by the wall of the new tool further repeatedly reflected out. As a result, Solar Dryer trapping heat from the sun, causing the temperature inside the appliance increases.

Based on the figure (3) can be known to the fluctuation in the value of air moisture with the length of drying time. This is directly affected by changes in temperature also fluctuates. When the comparison is made, it turns out the air inside the instrument has a relative humidity lower than outside. When moisture begins to evaporate from the material decline in relative humidity so it will reduce the water content (Rathore, 2010). This affects the drying speed levels are higher. In addition to the temperature, weather and light intensity, drying with solar drying method is also affected by the humidity in the dryer. In Figure 4.2 it can be seen that at the time of the drying air temperature is low, moist air at high dryer appliance. Air humidity will decrease with increasing temperature of the drying air, so that it can be concluded that the value of the air humidity is inversely proportional to the drying air temperature. (Chramsa, 2013)

\subsection{Moisture Content with Drying Time of Solar Dryer}

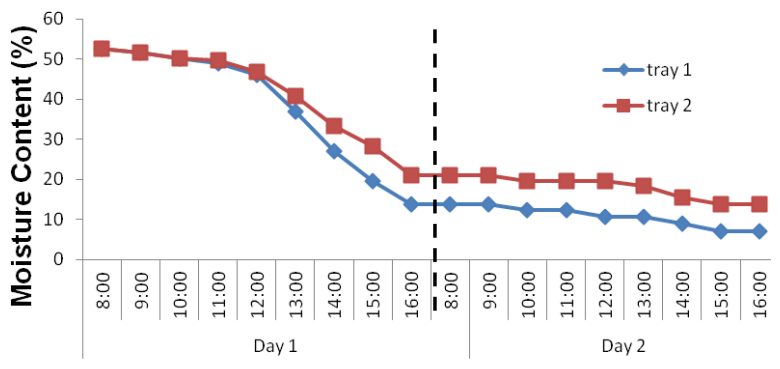

Time of the day (hours)

Fig. 4. Moisture Content with Drying Time of Solar Drying Method

Based on the figure (4) shows that there is a significant drop in water levels on the tray 1 from $49.03 \%$ to $27.07 \%$ occurred at $11.00 \mathrm{pm}$ until $14.00 \mathrm{pm}$ on the first day of testing and from $12.22 \%$ to $8.84 \%$ on the second day of testing that occurred at $11.00 \mathrm{pm}$ to $14.00 \mathrm{pm}$. On drying starch tray 1 by using solar dryers second day of testing at $15: 00 \mathrm{pm}$ moisture content of materials amounted to $7.05 \%$. In tray 2 a decline in water levels significantly from $49.57 \%$ to $33.23 \%$ occurred at 11.00 pm until $14.00 \mathrm{pm}$ on the first day of testing and from $19.66 \%$ to $15.35 \%$ on the second day of testing, which occurred at 11.00 am to $14.00 \mathrm{pm}$. On drying starch tray 2 by the method of solar dryers second day of testing at 15:00 pm moisture content of materials amounted to $13.81 \%$. This indicates that the products meet the standard of a maximum moisture content in accordance with SNI for tapioca starch product that is less than $15 \%$ (Taihua, 2017). 


\subsection{Drying Rate with Drying Time of Solar Dryer}

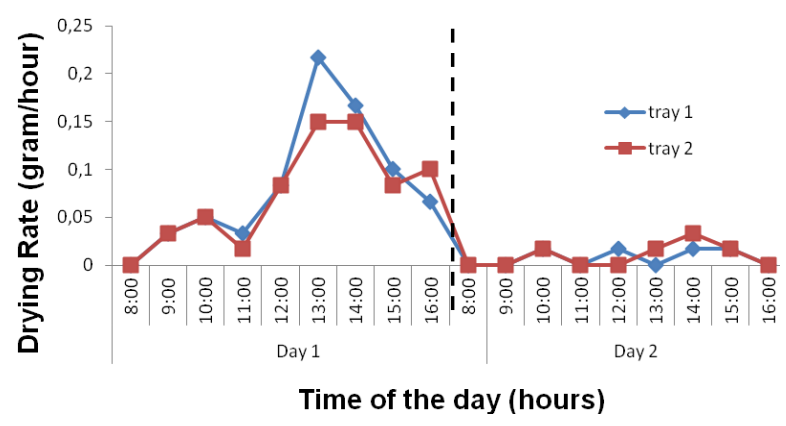

Fig. 5. Drying Rate and Drying Time of Solar Drying Method

Based on the figure (5) shows the comparison of drying rate with respect to time. Fluctuations can be seen in the rate of drying by the method of the solar dryers. In tray 1 drying rate increased significantly when the 11:00 am until 13:00 pm which is $0.03 \mathrm{~g} / \mathrm{h}$ to 0.21 grams / hour on the first day and remained constant at $11.00 \mathrm{pm}$ until $14.00 \mathrm{pm}$ which is 0.016 grams / hour on a second. In tray 2 actually increased drying time of 11:00 am until $14: 00 \mathrm{pm}$ that is 0,016 grams / hour up to 0.15 grams / hour on the first day and on the second day from 13:00 am until 14:00 pm that is 0,016 grams / hour up to 0,033 grams / hour, So the longer the drying time will make increasing the drying rate is directly proportional to the weight loss that occurred (Dhanushkodi, 2014)

\subsection{Dryer Efficiency with Drying Time of Solar Dryer}

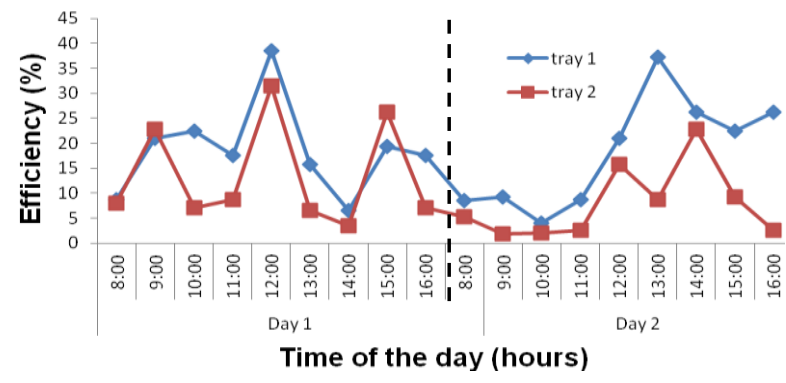

Fig. 6. Dryer Efficiency and Drying Time of Solar Drying Method

Based on the figure (6) can be seen on the tray 1 maximum efficiency is $38.5 \%$ on the first day and $37.25 \%$ on the second day of drying. In the second tray is a maximum efficiency of $31.5 \%$ on the first day and $22.7 \%$ on the second day of drying. The maximum drying efficiency occurred at $12.00 \mathrm{pm}$ on the first day and 13:00 pm until 14:00 pm on the second day where the intensity of the sun is high and the optimal temperature dryer at that hour. The drying efficiency solar dryers follow the same pattern with the intensity of the sun. So the optimum drying efficiency occurred at $12.00 \mathrm{pm}$ due to the high intensity of the sun affected. (Dhanushkodi, 2014)

\section{Conclusion}

Results of the drying of starch with methods of solar dryer can be concluded that the air humidity will decrease with increasing solar radiation and air temperature dryer, it can be concluded that the value of the air humidity is inversely proportional to the solar radiation and air temperature dryer. Drying tapioca flour with solar dryers method can dry ingredients until the water content of $7.05 \%$ in a faster time. Analysis of temperature and relative humidity where the maximum achievable temperature is $49^{\circ} \mathrm{C}$. The humidity will decrease with increasing temperature of the drying air, so that it can be concluded that the value of the air humidity is inversely proportional to the drying air temperature. The maximum drying rate in this study was 0.21 grams / hour, where the value of solar dryers dryer efficiency is $38.5 \%$. Tapioca starch drying method produces solar dryers to dry tapioca starch product more desirable in terms of color, aroman and contaminants in products rather than drying tapioca with sun conventional methods. Therefore, solar dryers can be an alternative means of dryers in food substance drying.

\section{References}

1. J. D. Anhalt,. World Climate and Energy Event, Rio de Janeiro, Brazil, 44-53. (2003).

2. A. Azimi, T. Tavakoli, H.K. Beheshti, A. Rahimi, Iran. J. Energy Environ. 3. 347-353. (2012).

3. S. Dhanuskodi, V. Wilson, \& S. Kumarasamy, Facta Universitatis, Series: Mechanical Engineering, 12, 277-288. (2014).

4. M.Ordoñez, \& A. Herrera., Powder technol. 253, 8997. (2014).

5. N. A.Aviara, L. N. Onuoha, O. E. Falola, \& J. C. Igbeka, Energy and exergy analyses of native cassava starch drying in a tray dryer. Energy, 73, 809-817. (2014).

6. N. S. Rathore, N. L. Panwar. Renewable Sustainable Energy Rev., 16, 37-43.(2010).

7. O. U. Dairo, A. A.Aderinlewo, O. J., Adeosun, I. A. Ola, \& T. Salaudeen., Acta Technologica Agriculturae, 18, 102-107. (2015).

8. S. Aichayawanich, M. Nopharatana. A. Nopharatana, \& W. Songkasiri,. Carbohydr. polym., 84, 292-298. (2011).

9. Standar Nasional Indonesia 3451:. Tapioka. www.bsn.go.id (2011)

10. Taihua Mu, Hongnan Sun, Miao Zhang dan Cheng Wang. Sweet Potato Processing Technology. Beijing : Academic Press Chinese Academy of Agricultural Sciences. (2017).

11. E.Tarigan, P.Tekasakul, Proceedings of the Australia and New Zealand Solar Energy Society Annual Conference. 1-9. 2005,

12. W. Chramsa-Ard, S. Jindaruksa, C. Sirisumpunwong \& S. Sonsaree, Energy Procedia, 34.189-197. (2013). 